\title{
PENGELOLAAN KESAN MAHASISWA PENGGUNA OOTD STYLE DI INSTAGRAM
} (Studi Dramaturgi pada Mahasiswa Pengguna Foto OOTD di akun @ootdupi)

\begin{abstract}
Abstrak
Instagram menjadi sebuah media sosial yang digandrungi oleh kaum remaja khususnya mahasiwa. OOTD Style menjadi sebuah trend fashion yang terus berkembang mengikuti zaman dengan menunjukkan outfit yang dipakainya di hari itu. Permainan peran dilakukan oleh mahasiswa pengguna OOTD Style melalui pengelolaan kesan yang dibuat untuk dapat tampil sebaik-baiknya hingga mendapatkan predikat sebagai mahasiswa yang fashionable. Fokus penelitian ini adalah untuk mengetahui penampilan panggung depan dan panggung belakang serta mendeskripsikan pengelolaan kesan mahasiswa pengguna OOTD Style yang di repost olehakun @ootdupi di media sosial Instagram. Penelitian ini menggunakan metode kualitatif dan format deskriptif dengan pendekatan dramaturgi berdasarkan paradigma konstruktivis. Informan terdiri dari tiga informan utama dan satu informan pendukung. Teknik pengumpulan data yang digunakan yaitu melalui wawancara, observasi dan dokumentasi. Hasil penelitian menunjukkan bahwa image yang dibangun oleh mahasiswa pengguna OOTD Style yaitu melalui dramaturgi dan pengelolaan kesan di Instagram sebagai panggung depannya. Kesan fashionable ditunjukkan oleh ketiga informan melalui pemilihan outfit yang dipakai hingga berbagai macam hal penunjang lainnya agar foto outfit of the day yang ditunjukkan ketiga informan di Instagram terlihat lebih menarik.
\end{abstract}

Kata Kunci: Pengelolaan Kesan, Dramaturgi, Instagram, OOTD Style 
PENDAHULUAN

Diawali dari munculnya Blog, Friendster, MySpace dan pada tahun 2004 hingga sekarang ini, lahirlah Facebook, Twitter, Path dan Instagram yang membuat media sosial semakin booming dan diminati oleh masyarakat Indonesia. Fenomena Facebook dan Twitter pun membuat gempar dunia new media karena penggunanya yang selalu meningkat tiap tahun. Di tahun 2016 hingga sekarang, situs pemeringkat website dunia www.alexa.com menyebutkan Instagram menjadi sebuah media sosial terpopuler atau banyak digunakan di Indonesia jauh mengungguli Facebook dan Twitter.

Dengan semakin fenomenalnya media sosial terutama Instagram, memunculkan sebuah fenomena baru di kalangan fashion yaitu Outfit of the Day Style atau disingkat dengan OOTD Style. OOTD merupakan padanan kata untuk menunjukan apa yang dipakai di hari itu. Konsep OOTD sangat sederhana, dan tidak terlalu dibuat-buat. Dalam artian, itu adalah outfit pribadi yang benar-benar mereka pakai untuk beraktivitas dalam satu hari (wolipop.detik.com).

Di dalam konsep dramaturgi, kehidupan sosial manusia seolah dimaknai sama dengan pertunjukan drama sehingga ada aktor yang memainkan perannya. Di Instagram, pengguna menjadi seorang aktor yang memainkan peran sesuai dengan kesan yang diharapkan sehingga pengguna lain akan memiliki persepsi mengenai kehidupan sosial dan gaya hidup pengguna. Misalkan, jika pengguna ingin mendapatkan kesan memiliki kepopuleran yang tinggi maka dia akan menampilkan gambaran diri sebaik-baiknya dengan meng-unggah foto dengan menampilkan sisi fashionable dan menggunakan busana yang dianggap kekinian agar terlihat trendi dan moderen.

Oleh karena itu, peneliti ingin mengetahui bagaimana pengelolaan kesan yang dibuat dan dimunculkan oleh mahasiswa UPI yang dimana foto OOTD-nya telah di-repost oleh akun Instagram @ootdupi. Dilihat dari fenomena penggunaan foto OOTD di Instagram yang mengarah kepada gejala-gejala untuk menunjukkan status sosial, maka peneliti ingin lebih

tahu apa saja yang harus ditampilkan ketika melakukan foto OOTD dan mengunggahnya ke 
Instagram melalui berbagai macam hal menunjang yang mendukung melalui petunjukpetunjuk untuk menimbulkan kesan pada diri, yakni panggung (setting), penampilan (appearance), dan gaya bertingkah laku (manner) yang masuk ke dalam Front Stage, lalu bagaimana perilaku dan outfit informan sehari - hari saat tidak ada di depan panggung yang masuk ke dalam Back Stage dan bagaimana pengelolaan kesan yang dibuat oleh informan agar tetap menjaga image dirinya sebagai mahasiswa pengguna OOTD Style.

\section{TINJAUAN PUSTAKA}

\section{New Media}

Pergeseran media dari media konvensional ke media baru dalam bentuk online telah membuat pola komunikasi berubah, dimana media online bisa membuat jarak yang jauh menjadi sangat dekat dan tidak terhalang oleh waktu karena internet dapat diakses kapan saja selama dua puluh empat jam. Tidak heran apabila media baru yang dikenal dengan internet ini lebih disukai daripada media massa konvensional seperti televisi, koran ataupun radio (Vivian, 2008: 263).

\section{Media Sosial}

Kaplan dan Haenlein (2010:59) mendefinisikan social media atau media sosial sebagai media yang menggunakan teknologi berbasis web untuk mengubah komunikasi menjadi dialog interaktif. Dengan kata lain, media sosial merupakan sebuah media online, di mana para penggunanya dapat dengan bebas dan mudah berbagi serta menciptakan isi pesan yang diinginkan.

Media sosial memberikan kesempatan untuk berinteraksi lebih dekat dengan konsumen. Media sosial menawarkan bentuk komunikasi yang lebih individual. Melalui media sosial para pemasar dapat mengetahui kebiasaan konsumen mereka dan melakukan interaksi secara personal serta membangun keterikatan yang lebih dalam (Puntoadi, 2011: 21). 


\section{Instagram \& OOTD (Outfit of the Day) Style}

Instagram, adalah salah satu sosial media yang memungkinkan penggunanya untuk berbagi foto atau video dengan pengguna lain bahkan dengan pengguna lain di sosial media lain. Hal itu diperkuat dengan pernyataan dari www.instagram.com sendiri mengartikan Instagram sebagai," Take a picture or video, choose a filter to transform its look and feel, then post to Instagram - it's that easy. You can even share to Facebook, Twitter, Tumblr and more. It's a new way to see the world".

Instagram memiliki fitur-fitur yang bisa digunakan oleh pengguna saat digunakan, Bambang (2012: 42) dalam bukunya Instagram Handbook menyatakan terdapat beberapa fitur yang ada di media sosial Instagram, diantaranya: unggah foto (photo upload), judul foto (caption), tagar (hashtag), tanda suka (like), Pengikut (followers), komentar (comment), mentions.

Outfit of the Day atau disingkat OOTD merupakan sebuah fenomena baru di media sosial Instagram terutama di kalangan fashion. OOTD merupakan padanan kata untuk menunjukan apa yang dipakai di hari itu. Konsep OOTD sangat sederhana, dan tidak terlalu dibuat-buat. Dalam artian, itu adalah outfit pribadi yang benar-benar mereka pakai untuk beraktivitas dalam satu hari. OOTD Style ini tidak hanya dilakukan oleh para fashionista saja, namun siapapun dapat melakukannya asalkan memiliki konsep foto yang sesuai dengan konsep OOTD (wolipop.detik.com). Tidak ada pembahasan khusus dari para ahli dalam mendefinisikan OOTD Style ini, kegiatan ini berkembang menjadi suatu kebiasaan yang dilakukan oleh para pengguna Instagram.

\section{Pengelolaan Kesan (Impression Management)}

Pengelolaan Kesan (Impression Management) adalah suatu bentuk dari upaya presentasi diri. Sering kali orang-orang melakukan pengelolaan kesan tanpa sadar, ada kalanya setengah sadar, namun juga dengan penuh kesadaran demi kepentingan pribadi, finansial, sosial dan politik tertentu (Mulyana, 2003:120). 
Pengelolaan kesan juga dapat didefinisikan sebagai teknik-teknik yang digunakan aktor untuk memupuk kesan-kesan tertentu dalam situasi tertentu untuk mencapai tujuan tertentu. Impression management atau pengelolaan kesan pertama kali diperkenalkan oleh Erving Goffman. Goffman berpendapat bahwa ketika orang-orang berinteraksi, mereka ingin menyajikan suatu gambaran diri atau presentasi diri yang akan diterima oleh orang lain. Busana, cara berjalan dan berbicara dapat digunakan untuk presentasi diri (Mulyana, 2003:112). Pengelolaan kesan dapat dibagi ke dalam dua kategori, yaitu:

a) Pengelolaan kesan melalui bahasa verbal

Pengelolaan kesan melalui bahasa verbal merupakan pengelolaan kesan melalui kata-kata atau bahasa. Hal ini merujuk kepada kata-kata atau bahasa yang digunakan seseorang dalam memupuk kesan-kesan pada dirinya.

b) Pengelolaan kesan melalui pesan nonverbal

Pengelolaan kesan melalui pesan nonverbal merupakan bagaimana kesan yang dibentuk seseorang dengan menggunakan bahasa tubuh atau isyarat. Menurut Ronald $B$ Adler dan George Rodman dalam buku teori komunikasi Sendjaja, bahasa nonverbal terdiri dari vokal, seperti nada suara, kualitas vokal. Sedangkan nonvokal terdiri dari, gerakan tubuh, penampilan dan ekspresi wajah (Sendjaja, 2004: 228).

\section{Dramaturgi}

Konsep Dramaturgi karya Erving Goffman dalam Mulyana (2006: 112) mengatakan bahwa Individu akan berlomba-lomba menampilkan dirinya sebaik mungkin. Goffman mengasumsikan bahwa ketika orang-orang berinteraksi, mereka ingin menyajikan suatu gambaran diri yang akan diterima orang lain. Upaya ini disebut sebagai pengelolaan kesan (impression management), yaitu teknik yang digunakan aktor untuk memupuk kesan-kesan tertentu dalam situasi tertentu untuk mencapai tujuan tertentu. Dalam konsep dramaturgi, kehidupan sosial manusia dimaknai sama seperti pertunjukkan drama dimana terdapat aktor yang memainkan perannya. 
Menurut Goffman, kehidupan sosial itu dapat dibagi menjadi "wilayah depan" (front region) dan "wilayah belakang" (back region). Wilayah depan ibarat panggung sandiwara bagian depan (front stage) yang ditonton khalayak penonton, sedangkan wilayah belakang ibarat panggung sandiwara bagian belakang (back stage) atau kamar rias tempat pemain sandiwara bersantai, mempersiapkan diri atau berlatih untuk memainkan perannya di panggung depan (Mulyana, 2008: 114).

Berikut penjelasan lebih detail mengenai kedua panggung sandiwara dalam teori Dramaturgi:

a) Front Stage (Panggung Depan)

Erving Goffman (dalam Mulyana, 2008: 38) menjelaskan bahwa wilayah depan (front region) adalah tempat atau peristiwa sosial yang memungkinkan individu menampilkan peran formal atau berperan layaknya seorang aktor. Wilayah ini juga disebut front stage (panggung depan) yang ditonton oleh khalayak, dimana wilayah depan ini merupakan bagian pertunjukkan yang umumnya berfungsi secara pasti dan umum untuk mendefinisikan situasi bagi orang yang menyaksikan pertunjukkan. Goffman membagi wilayah depan ini menjadi personal front (front pribadi) dan setting (panggung). Personal front dibagi menjadi dua yaitu appearance (penampilan) dan manner (tingkah laku).

b) Back Stage (Panggung Belakang)

Tempat untuk individu mempersiapkan perannya di wilayah depan, biasa juga disebut back stage (panggung belakang) atau kamar rias untuk mempersiapkan diri atau berlatih untuk memainkan perannya di panggung depan, di tempat ini pula para diri sang aktor bersantai, mempersiapkan diri, dan memunculkan siapa dirinya. Di tempat ini dilakukan semua kegiatan yang tersembunyi untuk melengkapi keberhasilan akting atau penampilan individu yang tidak sepenuhnya dapat dilihat, hal ini dapat memungkinkan bahwa tradisi dan karakter pelaku sangat berbeda dengan apa yang dipentaskan. Di panggung inilah individu akan tampil "seutuhnya" dalam arti identitas aslinya (Mulyana, 2008: 115). 


\section{METODOLOGI}

Jenis penelitian yang digunakan oleh penulis adalah penelitian kualitatif. Penelitian kualitatif berdasarkan penjelasan Patton dalam Ahmadi (2014:15) bahwa metode kualitatif adalah untuk memahami fenomena yang sedang terjadi secara alamiah (natural) dalam keadaan-keadaan yang sedang terjadi secara alamiah. Penelitian ini menggunakan metode studi deskriptif. Menurut Moleong dalam buku metodologi penelitian kualitatif menjelaskan bahwa studi deskriptif adalah data yang di kumpulkan berupa kata - kata, gambar dan bukan angka - angka. Hal itu disebabkan oleh adanya penerapan metode kualitatif. Selain itu, semua yang di kumpulkan berkemungkinan menjadi kunci terhadap apa yang sudah di teliti (Moleong, 2013: 11).

Penelitian ini menggunakan pendekatan Studi Dramaturgi. Peneliti melakukan penelitian mengenai bentuk pengelolaan kesan dengan pendekatan dramaturgi di media sosial Instagram. Goffman mengasumsikan bahwa ketika orang-orang berinteraksi, mereka ingin menyajikan suatu gambaran diri yang akan diterima orang lain. Menurut Goffman, kehidupan sosial itu dapat dibagi menjadi "wilayah depan" (front region) dan "wilayah belakang" (back region).

\section{PEMBAHASAN}

\section{a) Dramaturgi Panggung Depan}

Ketiga informan menggunakan media sosial Instagram sebagai ajang menunjukkan foto OOTD miliknya. Foto bergaya OOTD tersebut diunggah ke Instagram dengan terlebih dahulu mempersiapkan segala macam hal yang menunjang agar foto yang dihasilkan terlihat bagus dan menarik. Meskipun para informan merupakan mahasiswa biasa pada umumnya, namun disisi lain mereka menyadari bahwa pelaku OOTD setidaknya harus 
menjaga image dengan tetap menjaga penampilannya agar tetap terlihat fashionable di mata orang lain.

Mereka sangat berhati-hati dalam memposting foto OOTD, dimulai dari lokasi pengambilan foto, peralatan ruang yang mendukung seperti kamera atau editing tools, outfit yang digunakan saat melakukan foto OOTD, komposisi warna outfit ataupun feed Instagram, pemakaian aksesoris dan gerakan tubuh saat melakukan foto OOTD, karena bagaimanapun media sosial adalah sebagai ajang pencitraan dari kegiatan mereka berOOTD dan demi menunjukkan sebuah hasil foto yang terbaik. Oleh karena itu, peneliti membuat perbandingan panggung depan ketiga informan saat melakukan OOTD Style melalui sebuah tabel. 


\begin{tabular}{|c|c|c|c|}
\hline \multicolumn{4}{|c|}{ Panggung Depan (Front Stage) } \\
\hline Kriteria & Yaya & Kiko & Anggun \\
\hline $\begin{array}{l}\text { 1. Lokasi } \\
\text { Pengambilan } \\
\text { Foto }\end{array}$ & $\begin{array}{l}\text { Memilih lokasi } \\
\text { dengan background } \\
\text { putih }\end{array}$ & $\begin{array}{l}\text { Memilih lokasi dengan } \\
\text { background putih }\end{array}$ & $\begin{array}{l}\text { Memilih lokasi yang } \\
\text { Instagrammable dan } \\
\text { cerah }\end{array}$ \\
\hline $\begin{array}{l}\text { 2. Kamera yang } \\
\text { digunakan }\end{array}$ & $\begin{array}{l}\text { Memakai kamera } \\
\text { Handphone }\end{array}$ & Memakai kam & Memakai kamera SLR \\
\hline $\begin{array}{l}\text { 3. Editing Tools } \\
\text { Foto }\end{array}$ & $\begin{array}{l}\text { Menggunakan } \\
\text { editing tools foto }\end{array}$ & $\begin{array}{l}\text { Menggunakan editing } \\
\text { tools foto }\end{array}$ & $\begin{array}{l}\text { Menggunakan editing } \\
\text { tools foto }\end{array}$ \\
\hline $\begin{array}{l}\text { 4. Outfit saat } \\
\text { Melakukan Foto } \\
\text { OOTD }\end{array}$ & $\begin{array}{l}\text { Fleksibel dalam } \\
\text { memakai outfit saat } \\
\text { akan melakukan } \\
\text { foto OOTD (bisa } \\
\text { dipersiapkan atau } \\
\text { tidak sama sekali) }\end{array}$ & $\begin{array}{l}\text { Tidak mempersiapkan } \\
\text { outfit terlebih dahulu } \\
\text { saat akan melakukan } \\
\text { foto OOTD }\end{array}$ & $\begin{array}{l}\text { Mempersiapkan } \\
\text { terlebih dahulu saat } \\
\text { akan melakukan foto } \\
\text { OOTD }\end{array}$ \\
\hline $\begin{array}{l}\text { 5. Warna outfit } \\
\text { yang dipakai }\end{array}$ & $\begin{array}{l}\text { Memakai outfit } \\
\text { berwarna cerah } \\
\text { (orange, pink dan } \\
\text { putih) }\end{array}$ & $\begin{array}{l}\text { Memakai outfit } \\
\text { berwarna monokrom }\end{array}$ & $\begin{array}{lr}\text { Memakai } & \text { outfit } \\
\text { berwarna } & \text { dominan } \\
\text { biru } & \end{array}$ \\
\hline $\begin{array}{l}\text { 6. Tone (warna) di } \\
\text { Feed Instagram }\end{array}$ & $\begin{array}{ll}\text { Memakai } & \text { tone } \\
\text { (warna) } & \text { foto } \\
\text { monokrom } & \end{array}$ & $\begin{array}{l}\text { Memakai } \\
\text { (warna) } \\
\text { monokrom }\end{array}$ & $\begin{array}{lr}\text { Memakai } & \text { tone } \\
\text { (warna) random } & \text { ralkan cerah }\end{array}$ \\
\hline $\begin{array}{l}\text { 7. Pemakaian } \\
\text { Aksesoris }\end{array}$ & $\begin{array}{l}\text { Selalu memakai } \\
\text { aksesoris }\end{array}$ & \begin{tabular}{|ll}
$\begin{array}{l}\text { Selalu } \\
\text { aksesoris }\end{array}$ & \\
\end{tabular} & $\begin{array}{ll}\begin{array}{l}\text { Selalu memakai } \\
\text { aksesoris }\end{array} & \\
\end{array}$ \\
\hline $\begin{array}{l}\text { 8. Pemakaian } \\
\text { make-up }\end{array}$ & $\begin{array}{l}\text { Selalu memakai } \\
\text { make-up }\end{array}$ & $\begin{array}{l}\text { Tidak pernah } \\
\text { memakai make-up }\end{array}$ & $\begin{array}{l}\text { Selalu memakai make- } \\
\text { up }\end{array}$ \\
\hline $\begin{array}{l}\text { 9. Gerakan Tub } \\
\text { saat Melakuk } \\
\text { Foto OOTD }\end{array}$ & $\begin{array}{l}\text { Melakukan foto } \\
\text { dengan gerakan } \\
\text { tubuh berdiri }\end{array}$ & $\begin{array}{lr}\text { Melakukan roto } \\
\text { dengan } & \text { gerakan } \\
\text { tubuh berdiri } & \\
\end{array}$ & $\begin{array}{lr}\text { Melakukan foto } \\
\begin{array}{l}\text { dengan } \\
\text { tubuh berdiri }\end{array} \\
\end{array}$ \\
\hline
\end{tabular}

\section{b) Dramaturgi Panggung Belakang}

Di panggung ini akan dibahas mengenai bagaimana kehidupan sehari-hari informan saat sedang tidak menjadi mahasiswa pengguna OOTD Style. Pada panggung ini aktor tidak lagi memainkan perannya, dimana individu akan bertindak seperti sewajarnya bagaimana identitas diri yang sebenarnya. Mahasiswa pengguna OOTD Style dapat bertindak berbeda 
dengan apa yang ditampilkannya di Instagram, seperti memiliki penampilan yang terbilang lebih cuek dan apa adanya.

Di kehidupan sehari-hari saat informan sedang tidak melakukan foto OOTD, mereka adalah mahasiswa biasa pada umumnya, hanya saja mereka memiliki side job yang berhubungan dengan bidang yang digelutinya yaitu dunia fashion. Selain itu, ketiga informan memiliki karakter yang senang bercanda dan banyak berbicara padahal dua informan lainnya yaitu Kiko dan Anggun menunjukkan karakter berbeda di panggung depan saat melakukan foto bergaya OOTD. Mengenai outfit yang dipakainya di kehidupan seharihari, kedua informan yaitu Yaya dan Kiko mengaku tidak jauh berbeda dengan apa yang ditampilkannya di Instagram, kecuali Anggun yang di kehidupan sehari-harinya lebih cuek dengan memakai outfit biasa saja, padahal di Instagramnya Anggun menunjukkan foto OOTD dengan outfit yang menarik dan stylish. Namun walaupun Yaya dan Kiko memakai outfit sehari-hari yang tidak jauh berbeda dengan apa yang ditunjukkannya di Instagram dan Anggun yang memakai outfit lebih cuek saat sehari-hari, tetap saja mereka menjaga outfit yang mereka pakai agar tetap fashionable di kehidupan sehari-hari karena sudah menjadi image dirinya masing-masing sebagai seseorang yang senang terhadap fashion.

Sama seperti panggung depan, peneliti membuat perbandingan panggung belakang ketiga informan di kehidupan sehari-hari saat sedang tidak melakukan foto OOTD Style melalui sebuah tabel.

\begin{tabular}{|c|l|l|ll|}
\hline \multicolumn{4}{|c|}{ Panggung Belakang (Back Stage) } \\
\hline \multicolumn{2}{|c|}{ Yaya } & \multicolumn{2}{c|}{ Kiko } & \multicolumn{2}{c|}{ Anggun } \\
\hline 1. Status & Mahasiswa & Mahasiswa Pendidikan & Mahasiswa IImu \\
Informan di & Manajemen Resort \& & Bahasa Perancis UPI & Komunikasi UPI \\
Kehidupan & Leisure UPI semester & semester akhir & semester enam \\
Sehari-hari & akhir & & \\
\hline
\end{tabular}




\begin{tabular}{|c|c|c|c|}
\hline $\begin{array}{l}\text { 2. Side Job } \\
\text { Informan }\end{array}$ & $\begin{array}{l}\text { MC dan menjadi } \\
\text { Wardah Beauty Agent } \\
\text { Bandung }\end{array}$ & $\begin{array}{l}\text { Fashion blogger } \\
\text { mengenai life style dan } \\
\text { content writer di } \\
\text { sebuah website fashion }\end{array}$ & $\begin{array}{l}\text { Memiliki bisnis } \\
\text { clothing online }\end{array}$ \\
\hline $\begin{array}{l}\text { 3. Karakter Diri } \\
\text { Mahasiswa } \\
\text { Pengguna } \\
\text { OOTD Style }\end{array}$ & $\begin{array}{l}\text { Memiliki } \quad \text { karakter } \\
\text { cerewet, senang } \\
\text { bicara dan selalu ceria }\end{array}$ & $\begin{array}{lr}\text { Memiliki } & \text { karakter } \\
\text { cheerful, } & \text { dan } \\
\text { hyperactive } & \end{array}$ & $\begin{array}{l}\text { Memiliki karakter suka } \\
\text { bercanda dan banyak } \\
\text { bicara }\end{array}$ \\
\hline $\begin{array}{l}\text { 4. Outfit Sehari- } \\
\text { hari } \\
\text { Mahasiswa } \\
\text { Pengguna } \\
\text { OOTD Style }\end{array}$ & $\begin{array}{l}\text { Memakai outfit jeans, } \\
\text { sandal biasa, sepatu } \\
\text { kets, sweater atau } \\
\text { cardigan } \\
\text { dengan apa yang } \\
\text { dipakainya } \\
\text { melakukan saat } \\
\text { OOTD) }\end{array}$ & $\begin{array}{l}\text { Memakai outfit kaos, } \\
\text { kemeja, sweater dan } \\
\text { sepatu boots (sama } \\
\text { dengan apa yang } \\
\text { dipakainya saat } \\
\text { melakukan foto OOTD) }\end{array}$ & $\begin{array}{l}\text { Memakai outfit kaos, } \\
\text { jeans dan sepatu } \\
\text { (berbeda dengan apa } \\
\text { yang dipakainya saat } \\
\text { melakukan foto OOTD) }\end{array}$ \\
\hline
\end{tabular}

\section{c) Analisis Pengelolaan Kesan}

Pengelolaan kesan oleh mahasiswa pengguna OOTD Style merupakan upaya yang dilakukan secara sengaja demi kepentingan pribadinya, yaitu dengan menjaga image yang mereka bangun melalui bahasa verbal yaitu pembuatan caption di foto OOTD yang diunggahnya ke Instagram dan bahasa nonverbal melalui ekspresi wajah dan tatapan mata saat sedang melakukan foto OOTD. Hal ini dilakukan agar mahasiswa pengguna OOTD Style menjadi sosok yang ia harapkan, menjadi seseorang yang fashionable dan cinta terhadap fashion. 
Pengelolaan kesan secara verbal ditunjukkan oleh mahasiswa pengguna OOTD Style melalui sebuah caption yang diunggah bersamaan dengan foto OOTD miliknya di Instagram. Caption foto yang dibuat oleh mahasiswa pengguna OOTD Style di Instagram berbeda-beda, ada caption berupa quotes ataupun caption dengan unsur komedi dan tidak jarang pula caption yang berisi mengenai produk endorse. Walaupun caption berisikan quotes ataupun hal lucu, namun tetap disesuaikan dengan outfit yang dipakainya saat itu. Caption-caption tersebut dibuat berdasarkan mood yang sedang dirasakan oleh informan, kecuali pada saat mendapatkan endorse yang biasanya memakai caption sesuai dengan produk yang diiklankan.

Ekspresi wajah dan tatapan mata informan saat sedang melakukan foto OOTD Style merupakan bagian bentuk pengelolaan kesan nonverbal, dimana kesan yang dibentuk yaitu menggunakan bahasa tubuh atau isyarat. Ketiga informan mempunyai alasan tersendiri mengenai raut wajah yang senyum atapun datar saat mereka melakukan foto OOTD Style dan juga tatapan mata yang melihat kamera atau candid. Seperti Yaya yang senang memasang ekspresi wajah tersenyum dan melihat kamera, hal tersebut dilakukannya dengan alasan terlihat lebih lucu. Berbeda dengan Kiko dan Anggun dimana mereka berdua lebih senang memasang ekspresi wajah datar dan tidak senyum, hal tersebut dilakukannya dengan alasan tidak percaya diri jika tersenyum, lalu tatapan mata lebih memilih tidak melihat ke kamera atau candid dengan alasan agar terlihat lebih natural seperti keseharian.

Mahasiswa pengguna OOTD Style menganggap bahwa menjaga image atau reputasi yang mereka tunjukkan di panggung depan merupakan hal yang penting yaitu untuk untuk menunjukkan sisi fashionable yang mereka miliki di mata orang lain. Selain itu, image digunakan untuk mempertahankan dan menunjang side job yang mereka tekuni yang berkecimpung tidak jauh dari dunia fashion. Ketiga informan pun mengaku bahwa mereka akan tetap menjaga outfit mereka yang fashionable saat di kehidupan sehari-hari, namun walaupun tetap menjaga image, mereka mengakui tidak berlebihan dan tetap apa adanya. 
Pengelolaan kesan yang dibangun oleh mahasiswa pengguna OOTD Style, menimbulkan sebuah persepsi yang diharapkan yaitu ingin mendapatkan pengakuan sebagai seseorang yang fashionable. Pengelolaan kesan tersebut di bangun dari outfit yang mereka pakai saat melakukan foto OOTD dan berbagai macam hal lainnya yang menunjang foto OOTD Style semakin menarik. Fashionable yang didefinisikan oleh ketiga informan yaitu dengan tidak terlalu memperhatikan mode atau apa yang sedang trend, namun bagaimana seseorang tetap nyaman dan percaya diri memakai outfit tersebut, hingga nantinya akan memiliki karakter outfit yang berbeda dengan orang lain.

\begin{tabular}{|c|c|c|c|}
\hline \multicolumn{4}{|c|}{ Pengelolaan Kesan (Impression Management) } \\
\hline Kriteria & Yaya & Kiko & Anggun \\
\hline $\begin{array}{l}\text { 1. Pemakaian } \\
\text { Caption di Foto } \\
\text { OOTD yang } \\
\text { diunggah }\end{array}$ & $\begin{array}{l}\text { Memakai caption foto } \\
\text { OOTD di Instagram } \\
\text { yang disesuaikan } \\
\text { dengan mood saat itu }\end{array}$ & $\begin{array}{l}\text { Memakai caption } \\
\text { foto OOTD di } \\
\text { Instagram yang } \\
\text { disesuaikan dengan } \\
\text { mood saat itu }\end{array}$ & $\begin{array}{l}\text { Memakai caption } \\
\text { foto oOTD di } \\
\text { Instagram } \\
\text { disesuaikan dengan } \\
\text { mood saat itu }\end{array}$ \\
\hline $\begin{array}{l}\text { 2. Ekspr } \\
\text { dan T }\end{array}$ & $\begin{array}{l}\text { Memasang ekspresi } \\
\text { wajah tersenyum dan } \\
\text { melihat ke kamera }\end{array}$ & $\begin{array}{l}\text { Memasang ekspresi } \\
\text { wajah datar, tidak } \\
\text { tersenyum dan tidak } \\
\text { melihat ke kamera } \\
\text { (candid) }\end{array}$ & $\begin{array}{l}\text { Memasang ekspresi } \\
\text { wajah datar, tidak } \\
\text { tersenyum dan tidak } \\
\text { melihat ke kamera } \\
\text { (candid) }\end{array}$ \\
\hline $\begin{array}{l}\text { 3. Menjaga Image } \\
\text { yang Telah } \\
\text { dibangun di } \\
\text { Instagram }\end{array}$ & $\begin{array}{l}\text { Akan tetap menjaga } \\
\text { image sebagai } \\
\text { mahasiswa pengguna } \\
\text { OOTD Style }\end{array}$ & $\begin{array}{l}\text { Akan tetap menjaga } \\
\text { image sebagai } \\
\text { mahasiswa } \\
\text { pengguna OOTD } \\
\text { Style }\end{array}$ & $\begin{array}{l}\text { Akan tetap menjaga } \\
\text { image sebagai } \\
\text { mahasiswa } \\
\text { pengguna OOTD } \\
\text { Style }\end{array}$ \\
\hline
\end{tabular}




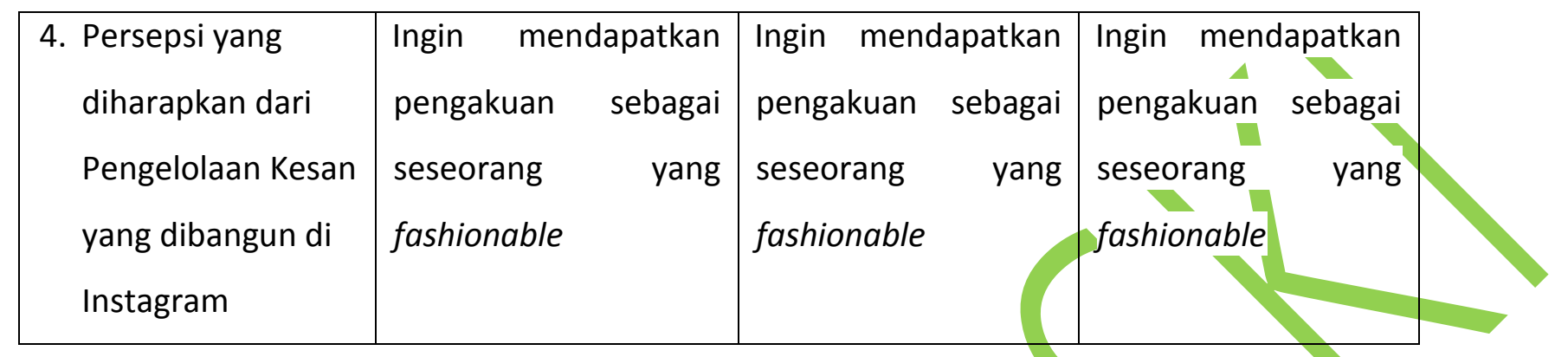

\section{KESIMPULAN}

1. Front Stage (Panggung Depan)

Pemetaan panggung depan ketiga informan diketahui bahwa Instagram digunakan sebagai panggung depan media berbagi foto OOTD miliknya. Berbagai macam komponen untuk menunjang informan dalam melakukan foto OOTD Style diantaranya: pemilihan lokasi, peralatan ruang yang mendukung meliputi tipe kamera dan editing tools foto, outfit yang digunakan, pemilihan warna outfit dan tone foto Instagram, peralatan pendukung dalam menunjang penampilan seperti aksesoris maupun make-up dan terakhir yaitu gerakan tubuh yang dilakukan saat melakukan foto OOTD.

Dari semua komponen-komponen tersebut yang informan lakukan di Instagram pribadinya, mempunyai tujuan yaitu ingin menampilkan sebuah hasil foto outfit of the day yang menarik yang juga sesuai dengan kriteria akun Instagram @ootdupi. Selain itu, informan ingin menunjukkan sosok diri sebagai seseorang yang senang terhadap fashion dan memiliki predikat sebagai mahasiswa yang fashionable.

2. Back Stage (Panggung Belakang)

Pemetaan panggung belakang menunjukkan bahwa kehidupan sehari-hari informan sebagai mahasiswa Universitas Pendidikan Indonesia (UPI) yang biasa saja layaknya mahasiswa pada umumnya. Panggung belakang merupakan moment yang tidak ditampilkan dan jarang sekali dipublikasikan informan. Namun dibalik menjadi mahasiswa biasa pada umumnya, ketiga informan memiliki side job yang masih berhubungan dengan fashion yang memang disukainya. 
Hasil analisis panggung belakang menunjukkan bahwa terdapat persamaan karakter dari salah satu informan yaitu Yaya, yang mengaku bahwa karakter di kehidupan seharihari sama dengan apa yang ditampilkannya di Instagram, namun berbeda dengan kedua informan lainnya dimana terdapat perbedaan karakter di kehidupan sehari-hari yang senang bercanda dan selalu ceria namun saat di Instagram kedua informan memasang raut muka yang flat dan cuek. Mengenai outfit yang dipakai mahasiswa pengguna OOTD Style saat di panggung belakang, tidak jauh berbeda dengan apa yang ditampilkan di Instagram, kecuali salah satu informan yaitu Anggun yang di kehidupan sehari-harinya lebih cuek dengan memakai outfit biasa saja, padahal di Instagramnya, Anggun menunjukkan foto OOTD dengan outfit yang menarik dan stylish. Mahasiswa pengguna OOTD Style lebih bebas untuk bersikap saat sedang berada di panggung belakang, hanya saja pemakaian outfit yang tetap dijaga, yang walaupun biasa saja namun tetap terlihat fashionable.

3. Impression Management (Pengelolaan Kesan)

Pengelolaan kesan yang dibuat oleh ketiga informan dalam melakukan foto OOTD Style yaitu melalui pengelolaan kesan secara verbal yang salah satunya dengan membuat sebuah caption untuk foto OOTD yang akan diunggah ke Instagram. Caption yang dibuat berbeda-beda berisikan berbagai macam hal yang disesuaikan tergantung tema foto OOTD yang diunggah dan juga mood yang sedang dirasakan oleh informan. Selain secara verbal, secara non verbal adalah ekspresi wajah dan tatapan mata yang ditunjukkan informan ketika sedang melakukan foto OOTD Style. Ekspresi wajah yang senyum dan tatapan mata melihat ke kamera diakui Yaya terlihat lebih lucu dan ekspresi wajah datar atau cuek disertai tatapan mata candid, diakui kedua informan lainnya terlihat lebih natural.

Ketiga informan sebagai mahasiswa pengguna OOTD Style menganggap bahwa menjaga image atau reputasi yang mereka tunjukkan di panggung depan yaitu Instagram merupakan hal yang penting yaitu untuk untuk menunjukkan sisi fashionable yang 
mereka miliki di mata orang lain. Selain itu, image digunakan untuk mempertahankan dan menunjang side job yang mereka tekuni yang berkecimpung tidak jauh dari dunia fashion. Persepsi yang diharapkan oleh informan yaitu mendapatkan pengakuan sebagai seseorang yang fashionable yang di bangun dari outfit yang mereka pakai saat melakukan foto OOTD dan berbagai macam hal lainnya yang menunjang foto OOTD Style miliknya semakin menarik. 


\section{DAFTAR PUSTAKA}

Atmoko Dwi, Bambang. 2012. Instagram Handbook Tips Fotografi Ponsel. Jakarta: Media Kita.

Kaplan, Andreas. M. dan Haenlein, Michael. 2010. Users of the world, unite! The challenges and opportunities of Social Media. Business Horizons.

Moleong, Lexy J. 2013. Metodologi Penelitian Kualitatif: Edisi Revisi (Cetakan keduapuluh sembilan). Bandung: Remaja Rosdakarya.

Mulyana, Deddy. 2003. Metodologi Penelitian Kualitatif: Paradigma Baru Ilmu Komunikasi dan IImu Sosial Lainnya. Bandung: Rosdakarya.

Mulyana, Deddy. 2006. Pengantar Ilmu Komunikasi. Bandung: Remaja Rosdakarya.

Mulyana, Deddy. 2008. Metodologi Penelitian Kualitatif, Paradigma Baru Ilmu Komunikasi dan Ilmu Sosial Lainnya. Bandung: Remaja Rosdakarya.

Puntoadi, Danis, 2011. Menciptakan Penjualan Melalui Social Media. Jakarta: Elex Komputindo.

Sendjaja, Djuarsa. 2004. Pengantar IImu Komunikasi. Jakarta: PT. Raja Grafindo Persada

Vivian, John. 2008. Teori Komunikasi Massa (Edisi Kedelapan). Jakarta: Kencana. 